\title{
Prevalence of Abnormal Cervical Lesions and Associated Factors Among Women in Harar, Eastern Ethiopia
}

This article was published in the following Dove Press journal: Cancer Management and Research

\author{
Elias Bekele Wakwoya (iD ${ }^{1}$ \\ Kasiye Shiferaw Gemechu (iD ${ }^{2}$ \\ 'Department of Midwifery, College of \\ Health Sciences, Arsi University, Assela, \\ Ethiopia; ${ }^{2}$ School of Nursing and \\ Midwifery, College of Health and Medical \\ Sciences, Haramaya University, Harar, \\ Ethiopia
}

Purpose: The primary objective of this study was to determine the prevalence of abnormal cervical lesions and associated factors and the secondary objective was to assess adherence to post-cryotherapy treatment recommendations, among women in Harari region, eastern Ethiopia.

Materials and Methods: This study was conducted in two public hospitals in Harar city from January 1 to May 30, 2019. A facility-based descriptive cross-sectional study was conducted and a total of 1181 women were included in the study. Structured face-to-face interviews with women aged 25-49 years were used to collect information on precancerous cervical lesion screening and adherence to post-cryotherapy treatment. Visual inspection with acetic acid (VIA) method was used to screen women for precancerous cervical lesions. The collected data were entered into Epi Info software and then exported to SPSS software for analysis. Logistic regression analysis was used to check the association between independent variables and abnormal cervical lesions.

Results: The prevalence of abnormal cervical lesions among the participants screened was $24.5 \%(95 \% \mathrm{CI}=20.8-27.9 \%)$. Having no formal education $(\mathrm{AOR}=2.68,95 \% \mathrm{CI}=$ $1.32-5.46)$, lack of awareness of cervical cancer, $(\mathrm{AOR}=2.65,95 \% \mathrm{CI}=1.68-4.23)$ and having a husband with history of multiple sexual partners $(\mathrm{AOR}=1.75,95 \% \mathrm{CI}=1.13-2.7)$ were independently associated with abnormal cervical lesions. From the respondents who received cryotherapy treatment prior to the study, the majority, $92.9 \%(95 \% \mathrm{CI}=76.5-99.1)$, adhered to the post-cryotherapy treatment recommendations.

Conclusion: We found that the prevalence of abnormal cervical lesions in this area was high. Having no formal education, lack of awareness of cervical cancer and having a husband with history of multiple sexual partners were independently associated with having abnormal cervical lesions. The federal ministry of health and other stakeholders should focus on the primary prevention method (HPV vaccination) at an earlier stage to reduce the prevalence of abnormal cervical lesions in the study area. Harari regional health bureau should provide awareness creation activities and special attention should be given to uneducated women.

Keywords: abnormal cervical lesions, adherence, cryotherapy, Ethiopia

\section{Introduction}

Cervical cancer is a continuous major public health problem, ranking as the fourth most common cause of cancer incidence and mortality in women worldwide. Around $84 \%$ of all cervical cancers and $88 \%$ of deaths caused by cervical cancer occur in low income countries. In these countries $1.8 \%$ of women were diagnosed with and $1.3 \%$ died from cervical cancer. In 2018, cervical cancer was the main
Correspondence: Elias Bekele Wakwoya Department of Midwifery, College of Health Sciences, Arsi University, 04,

Assela, Ethiopia

Tel +25l 913070421

Email eliasbekelel83@gmail.com
Cancer Management and Research 2020:I2 12429-I2437

12429

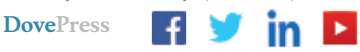

http://doi.org/10.21 
cause of cancer-related deaths in women in Africa. As Ethiopia is one of the countries in this region obviously it is severely affected by the disease. Recent evidence indicated that 6294 and 4884 women were diagnosed with and die of cervical cancer respectively in Ethiopia. ${ }^{1-3}$

Persistent human papilloma virus (HPV) infection type 16 and 18 causes epithelial cells of the cervix to grow in an abnormal fashion. This usually results in precancerous lesions and if these lesions are left untreated it can develop into invasive cancer. ${ }^{4-6}$ Before becoming invasive, cervical cancer remains at precursor stage for many years and this provides a golden opportunity for early detection and treatment. ${ }^{7}$ Visual inspection with acetic acid (VIA) is cost effective, valid, and has been shown to be a convenient method of cervical cancer screening in developing countries. ${ }^{8}$ The single visit approach (SVA) strategy was designed to minimize "lost to follow up treatment" due to delay between screening and treatment service. This approach helps the women who tested positive to receive the treatment on the same day of the screening. ${ }^{9}$ In Ethiopia the single visit approach was first launched in 2009 and the service was first provided to HIV positive women at 14 selected public health facilities. ${ }^{10}$

Previous studies in Ethiopia showed there are differences in the prevalence of abnormal cervical lesions among women living in different parts of the country. According to the study from south west Ethiopia, 12.9\% of women screened by VIA technique were positive and $1.2 \%$ had a lesion suspected to be cancer. ${ }^{11}$ Studies from south and north east Ethiopia indicate, $22.1 \%$ and $9.9 \%$ of HIV positive women had precancerous cervical lesions. ${ }^{12,13}$ The identified factors associated with precancerous cervical lesions in the previous studies include; early coital debut, increased parity, having multiple sexual partners, husband's sexual history, history of sexually transmitted infections, use of oral contraceptives, family history of cervical cancer, smoking, and immunosuppression including HIV infection. ${ }^{14-18}$

The difference in prevalence of abnormal cervical lesions across parts of Ethiopia necessitates the determination of prevalence of abnormal cervical lesions in the eastern part of Ethiopia. To the best of our knowledge, there has been no similar study conducted in eastern part of Ethiopia. This study also assessed the adherence to post-cryotherapy treatment recommendations, which was not addressed by the previous studies in Ethiopia. ${ }^{11-14}$ The objective of this study was to assess the prevalence of abnormal cervical lesions and associated factors and adherence to post-cryotherapy treatment recommendations, among women in Harari region, eastern Ethiopia.

\section{Materials and Methods Study Setting, Period and Population}

This study was conducted in Hiwot Fana specialized university hospital and Jugal hospital in Harar city, eastern part of Ethiopia. Hiwot Fana specialized university hospital is one of the six government teaching hospitals in Ethiopia, providing health care services to more than 5 million people living in Harar city and its surroundings. Jugal Hospital is a regional referral hospital of the Harari National Regional State. Precancerous cervical lesion screening was launched in the year 2016 in both hospitals. This study was conducted from January 1 to May 30, 2019. The inclusion criteria were all non-pregnant women between 25 to 49 years of age and who visited either of the two hospitals during the study period. Exclusion criteria were; women who were severely ill and could respond to the questions, who were screened within the past 3 years and who had already been diagnosed with cervical cancer disease prior to the study.

\section{Sample Size and Sampling Procedure}

The required sample size was calculated by using a single population proportion formula based on the assumptions; standard error corresponding to $95 \%$ confidence interval level $(Z)=1.96$, proportion of women with positive precancerous cervical lesions taken from the previous study $(P)=(12.9 \%)^{11}$ and the margin of error $(d)=2 \%$. By adding a non-response rate of $15 \%$ the final sample size of 1240 was obtained. The sample size was distributed by proportional allocation based on the size of study population in each hospital and serial (convenience) sampling was used to recruit participants for this study.

\section{Data Collection Procedure and Ethical Consideration}

A structured and pretested questionnaire was used to collect information on sociodemographic characteristics of women, reproductive history, cervical cancer related history and adherence to post-cryotherapy treatment recommendations. All participants of this study completed the survey questions. Participants were invited to participate in the study when they came to get a service from gynecology OPD or ART clinic or family planning units. After verbal consent was obtained from the participants, exit 
interview was conducted by data collectors. The data collectors were trained nurses (bachelor of nursing qualification) and midwives recruited for this study and they were not health care providers working in these units. All participants received the health care services they came for, and were interviewed afterwards. Those women who were screened during three years prior to the study were asked about their experience relating to cryotherapy treatment and adherence to post-treatment recommendations. After the interview was completed, participants were invited to have precancerous cervical screening using VIA technique. Fifty-nine women refused to participate in this study and they were informed that not participating in this research did not affect the care they receive from the hospitals. Participants found to be VIA positive during screening were treated with cryotherapy and those who had suspicious lesions were referred for further tests and management. This study has obtained ethical approval from Haramaya University institutional health research Ethics review committee and the approval number was (COHMS/10.0/2968/18).

\section{Measurements and Data Quality Assurance}

To ensure the quality of data, training was given to data collectors (VIA screeners and interviewers). The VIA screeners were trained on cervical screening methods and cryotherapy for 5 days. The training mainly involved practical sessions to help the data collectors to acquire the skill effectively. Daily supervision and monitoring were done by well experienced senior staff to assure the quality of VIA screening. The result was considered as precancerous cervical lesions (positive VIA result) when dense aceto-white lesions with well-defined margins were observed within the vicinity of the transformation zone originating from the SCJ, or if the whole cervix or cervical growth turned white and persisted for one minute after application of diluted acetic. The result was considered as suspicious/suspected invasive $\mathrm{CC}$ when any cervical ulcer or growth was observed. In this study, abnormal cervical lesions were considered if the result was either positive or diagnosed as suspicious for cervical cancer after screening. The respondent was considered as adherent if she answered yes to one of the 2 questions on the questionnaire ("have you abstained from sexual intercourse for one month after treatment" or "if not abstained have you used condoms consistently for one month after treatment") and must have attended the follow up appointment. Multiple sexual partners was defined as having more than one lifetime sexual partner.

\section{Data Processing and Analysis}

The collected data were entered into Epi Info version 3.5.4 and then exported to SPSS version 23.0 software for analysis. Bivariate logistic regression was used to check the association between independent variables and abnormal cervical lesions. All variables which had $p$ value less than 0.2 in bivariate analysis remained in the model as potential confounders for multivariable analysis. Hosmer and Lemeshow's goodness-of-fit test was performed to ensure that the required assumption was fulfilled and variance inflation factor was low (between 1 and 2) for multicollinearity check. An adjusted odds ratio with 95\% confidence interval and a $\mathrm{p}$ value less than 0.05 was considered as a statistically significant association with the abnormal cervical lesions.

\section{Results}

A total of 1240 women were invited to participate in the study, and 1181 of participants responded to our study, making $95.2 \%$ response rate. Majority of the respondents were; Muslims (702 [59.4\%]), married (948 [80.3\%]) and Oromo (706 [59.8\%]) in ethnicity and the mean age of the respondents was 32.50 ( $\mathrm{SD} \pm 6.35)$ years. Nearly thirty four percent of respondents had no formal education and $821(69.5 \%)$ respondents were from urban areas (Table 1).

\section{Reproductive History}

The mean age at which the respondents started having sexual intercourse was 18.23 ( $\mathrm{SD} \pm 2.84$ ) years. Majority of respondents (975 [82.6\%]) gave birth to a child at least once and two thirds of them (645 [66.2\%]) had 1-3 babies. One fourth $(295$ [25\%]) of the respondents and 347 (29.4\%) of their husbands had history of sexual intercourse with more than one person. Ninety one $(7.7 \%)$ of the respondents and $68(5.8 \%)$ of the respondents' husbands were ever diagnosed with sexually transmitted infections (STI). Majority of the respondents (731 [62\%]) had regular menstrual cycles. Nearly fifty five percent of the respondents had ever used modern FP methods of which 264 (41\%) and 248 (38.3\%) used injectable and implants respectively. The mean duration of the FP methods used by respondents was $33.85(\mathrm{SD} \pm 27.86)$ months (Table 2). 
Table I Socio-Demographic Characteristics of Respondents at HFSUH and Jugal Hospital, January I to May 30, 2019

\begin{tabular}{|c|c|c|}
\hline Variables $(\mathbf{N}=|| 8 \mid)$ & Frequency & $\begin{array}{l}\text { Percent } \\
{[95 \% \mathrm{CI}]}\end{array}$ \\
\hline \multicolumn{3}{|l|}{ Age } \\
\hline $25-29$ & 625 & $52.9[50.0-55.8]$ \\
\hline $30-34$ & $24 I$ & $20.4[18.1-22.8]$ \\
\hline $35-39$ & 199 & $16.9[14.8-19.1]$ \\
\hline $40-49$ & 116 & $9.8[8.2-11.7]$ \\
\hline \multicolumn{3}{|l|}{ Marital status } \\
\hline Married & 948 & 80.3 [77.9-82.5] \\
\hline Single & 101 & $8.6[7.0-10.3]$ \\
\hline Divorced & 93 & $7.9[6.4-9.6]$ \\
\hline Widowed & 39 & $3.3[2.6-4.5]$ \\
\hline \multicolumn{3}{|l|}{ Religion } \\
\hline Muslim & 702 & $59.4[56.6-62.2]$ \\
\hline Orthodox & 372 & 31.5 [28.9-34.2] \\
\hline Protestant & 99 & $8.4[6.9-10.1]$ \\
\hline Others & 8 & $0.7[0.3-1.3]$ \\
\hline \multicolumn{3}{|l|}{ Ethnicity } \\
\hline Oromo & 706 & $59.8[56.9-62.6]$ \\
\hline Amhara & 335 & $28.4[25.8-31.0]$ \\
\hline Harari & 78 & $6.6[5.3-8.2]$ \\
\hline Tigray & 11 & $0.9[0.46-1.7]$ \\
\hline Others & 51 & $4.3[3.2-5.6]$ \\
\hline \multicolumn{3}{|l|}{ Occupation } \\
\hline Housewife & 573 & $48.5[45.6-5 \mid .4]$ \\
\hline Self-employed & 186 & $15.7[13.7-17.9]$ \\
\hline Government employees & 202 & $17.1[14.9-19.4]$ \\
\hline Daily laborer & 46 & $3.9[2.7-5.2]$ \\
\hline Merchant & 123 & $10.4[8.7-12.3]$ \\
\hline Others & 51 & $4.3[3.2-5.6]$ \\
\hline \multicolumn{3}{|l|}{ Educational status } \\
\hline No formal education & 398 & $33.7[31.0-36.5]$ \\
\hline Primary education $(\mathrm{I}-8)$ & 382 & $32.3[29.7-35.1]$ \\
\hline Secondary education $(9-10+2)$ & 234 & $19.8[17.6-22.2]$ \\
\hline 12th grade and above & 167 & $14.1[12.2-16.3]$ \\
\hline \multicolumn{3}{|l|}{ Place of residence } \\
\hline Urban & 821 & $69.5[66.8-72.1]$ \\
\hline Rural & 360 & $30.5[27.9-33.2]$ \\
\hline
\end{tabular}

\section{Cervical Cancer History and Related Variables}

Twenty four $(2 \%)$ and $35(3 \%)$ of the respondents had history of smoking and ever been on chronic steroids respectively. Thirty two $(2.7 \%)$ of the participants had history of abnormal cervical lesions and 28 $(2.4 \%)$ of the respondents reported that they had
Table 2 Reproductive History of Respondents at HFSUH and Jugal Hospital, January I to May 30, 2019

\begin{tabular}{|c|c|c|}
\hline Variables (N = II8I) & Frequency & Percent $[\mathrm{Cl}]$ \\
\hline \multicolumn{3}{|l|}{$\begin{array}{l}\text { Age at first sexual } \\
\text { intercourse }\end{array}$} \\
\hline$<15$ & 69 & $5.8[4.6-7.3]$ \\
\hline $15-19$ & 628 & $53.2[50.3-56.1]$ \\
\hline$>19$ & 484 & $41[38.2-43.8]$ \\
\hline \multicolumn{3}{|l|}{ Ever delivered baby } \\
\hline Yes & 975 & $82.6[80.3-84.7]$ \\
\hline No & 206 & $17.4[15.3-19.7]$ \\
\hline \multicolumn{3}{|l|}{$\begin{array}{l}\text { History of multiple sexual } \\
\text { partners }\end{array}$} \\
\hline Yes & 295 & $25.0[22.5-27.6]$ \\
\hline No & 886 & $75.0[72.4-77.5]$ \\
\hline \multicolumn{3}{|l|}{$\begin{array}{l}\text { History of husband's } \\
\text { multiple sexual partners }\end{array}$} \\
\hline Yes & 347 & $29.4[26.8-32.1]$ \\
\hline No & 834 & $70.6[67.9-73.2]$ \\
\hline \multicolumn{3}{|l|}{ Ever diagnosed with STI } \\
\hline Yes & 91 & $7.7[6.2-9.3]$ \\
\hline No & 1090 & $92.3[90.6-93.8]$ \\
\hline \multicolumn{3}{|l|}{$\begin{array}{l}\text { Husband ever diagnosed } \\
\text { with STI }\end{array}$} \\
\hline Yes & 68 & $5.8[4.5-7.2]$ \\
\hline No & 1113 & $94.2[92.7-95.5]$ \\
\hline \multicolumn{3}{|l|}{ Menstrual cycle } \\
\hline Regular & 731 & $61.9[59.1-64.7]$ \\
\hline Irregular & 363 & $30.7[28.1-33.5]$ \\
\hline Menopause & 87 & $7.4[5.9-9.0]$ \\
\hline \multicolumn{3}{|l|}{$\begin{array}{l}\text { Ever used modern FP } \\
\text { methods }\end{array}$} \\
\hline Yes & 647 & $54.8[51.9-57.6]$ \\
\hline No & 534 & $45.2[42.3-48.1]$ \\
\hline \multicolumn{3}{|l|}{ Method used $(n=647)$} \\
\hline Oral contraceptives & 108 & $16.6[13.8-19.8]$ \\
\hline Injectables (Depo) & 264 & $41.0[37.0-44.7]$ \\
\hline Implants & 248 & $38.3[34.6-42.2]$ \\
\hline IUCD & 27 & $4.1[2.8-6.0]$ \\
\hline \multicolumn{3}{|l|}{ Duration FP used $(n=647)$} \\
\hline$<12$ months & 193 & $29.3[26.3-33.5]$ \\
\hline 12-24 months & 154 & $23.8[20.6-27.3]$ \\
\hline$>24$ months & 300 & $46.4[42.5-50.3]$ \\
\hline
\end{tabular}

a family member who had been diagnosed with abnormal cervical lesions. More than three fourths of the participants (906 [76.7\%]) had been tested for HIV and one 
hundred and twenty six $(13.9 \%)$ of them were reactive of which $124(98.4 \%)$ were on highly active antiretroviral therapy (HAART) (Table 3).

\section{Adherence to Post-Cryotherapy} Treatment Recommendations

From the total respondents, $6.6 \%$ were screened for precancerous cervical lesion in the last three years prior to the study and $28(35.9 \%)$ of them were positive. All the respondents, $(28[100 \%])$ received cryotherapy treatment after VIA screening. Among those who received the treatment, $22(78.6 \%)$ were cured, $3(10.7 \%)$ were not cured and $3(10.7 \%)$ of the respondents did not know their status at the time of data collection. When respondents were asked to cite the information they received, majority of them (20 [71.4\%]) cited avoiding sexual intercourse for one month after the treatment. The greater proportion (25 [89.3\%]) of respondents reported that they had abstained from sexual intercourse for one month after

Table 3 Cervical Lesions History of Respondents at HFSUH and Jugal Hospital, January I to May 30, 2019

\begin{tabular}{|c|c|c|}
\hline Variables $(N=|| 8 \mid)$ & Frequency & Percent $[\mathrm{Cl}]$ \\
\hline $\begin{array}{l}\text { Ever smoked cigarettes } \\
\text { Yes } \\
\text { No }\end{array}$ & $\begin{array}{l}24 \\
1157\end{array}$ & $\begin{array}{l}2.0[1.3-3.0] \\
98.0[97.0-98.7]\end{array}$ \\
\hline $\begin{array}{l}\text { Diagnosed with cervical } \\
\text { lesions } \\
\text { Yes } \\
\text { No }\end{array}$ & $\begin{array}{l}32 \\
1149\end{array}$ & $\begin{array}{l}2.7[1.9-3.8] \\
97.3[96.2-98.1]\end{array}$ \\
\hline $\begin{array}{l}\text { Family member diagnosed } \\
\text { with cervical lesions } \\
\text { Yes } \\
\text { No }\end{array}$ & $\begin{array}{l}28 \\
1153\end{array}$ & $\begin{array}{l}2.4[1.6-3.4] \\
97.6[96.6-98.4]\end{array}$ \\
\hline $\begin{array}{l}\text { Chronic steroid use } \\
\text { Yes } \\
\text { No }\end{array}$ & $\begin{array}{l}35 \\
1146\end{array}$ & $\begin{array}{l}3.0[2.1-4.1] \\
97.0[95.9-97.2]\end{array}$ \\
\hline $\begin{array}{l}\text { Ever tested for HIV } \\
\text { Yes } \\
\text { No }\end{array}$ & $\begin{array}{l}906 \\
275\end{array}$ & $\begin{array}{l}76.7[74.2-79.1] \\
23.3[20.9-25.8]\end{array}$ \\
\hline $\begin{array}{l}\text { HIV test result }(\mathbf{n}=\mathbf{9 0 6}) \\
\text { Reactive } \\
\text { Nonreactive }\end{array}$ & $\begin{array}{l}126 \\
780\end{array}$ & $\begin{array}{l}13.9[11.7-16.3] \\
86.1[83.7-88.3]\end{array}$ \\
\hline $\begin{array}{l}\text { Currently on HAART }(\mathbf{n}= \\
\text { I26) } \\
\text { Yes } \\
\text { No }\end{array}$ & $\begin{array}{l}124 \\
2\end{array}$ & $\begin{array}{l}98.4[94.4-99.8] \\
1.6[0.1-5.6]\end{array}$ \\
\hline
\end{tabular}

the treatment. All participants (28 [100\%]) had attended the follow up visits after cryotherapy treatment. Overall, $92.9 \% \quad[95 \%$ CI $=76.5-99.1]$ of respondents who received the treatment adhered to the post-cryotherapy treatment recommendations (Table 4).

Table 4 Adherence to Post-Cryotherapy Treatment Recommendations Among Respondents at HFSUH and Jugal Hospital, January I to May 30, 2019

\begin{tabular}{|c|c|c|}
\hline Variables & Frequency & Percent $[\mathrm{Cl}]$ \\
\hline \multicolumn{3}{|l|}{$\begin{array}{l}\text { Screened with VIA in the } \\
\text { past } 3 \text { years }(N=|| 8 I)\end{array}$} \\
\hline Yes & 78 & $6.6[5.3-8.2]$ \\
\hline No & 1103 & $93.4[91.8-84.7]$ \\
\hline \multicolumn{3}{|l|}{$\begin{array}{l}\text { VIA screening result in the } \\
\text { past } 3 \text { years }(N=78)\end{array}$} \\
\hline Negative & 47 & $60.26[48.5-7 \mid .2]$ \\
\hline Positive & 28 & $35.9[25.3-47.6]$ \\
\hline Suspicious & 3 & $3.85[0.8-10.8]$ \\
\hline \multicolumn{3}{|l|}{ Treatment outcome } \\
\hline Cured & 22 & $78.6[59.0-91.7]$ \\
\hline Not cured & 3 & $10.7[2.3-28.2]$ \\
\hline Not declared & 3 & $10.7[2.3-28.2]$ \\
\hline \multicolumn{3}{|l|}{$\begin{array}{l}\text { Information received after } \\
\text { treatment }\end{array}$} \\
\hline $\begin{array}{l}\text { Avoid sexual intercourse for } \\
\text { I month }\end{array}$ & 20 & $71.4[51.3-86.8]$ \\
\hline Avoid douching for I month & 18 & $64.3[44.1-81.4]$ \\
\hline $\begin{array}{l}\text { Use condoms if not } \\
\text { abstaining }\end{array}$ & 6 & $21.4[8.3-40.9]$ \\
\hline \multicolumn{3}{|l|}{$\begin{array}{l}\text { Abstained from sex for I } \\
\text { month }\end{array}$} \\
\hline Yes & 25 & $89.3[71.8-97.7]$ \\
\hline No & 3 & $10.7[2.3-28.2]$ \\
\hline \multicolumn{3}{|l|}{ Reason for not abstaining } \\
\hline Abstaining is not important & I & $33.3[0.8-90.6]$ \\
\hline Forgot the recommendation & 2 & $66.6[9.4-99.2]$ \\
\hline \multicolumn{3}{|l|}{$\begin{array}{l}\text { Used condoms for one } \\
\text { month }\end{array}$} \\
\hline Yes & I & $3.6[0.09-18.3]$ \\
\hline No & 27 & 96.4 [81.6-99.9] \\
\hline \multicolumn{3}{|l|}{$\begin{array}{l}\text { Reason for not using } \\
\text { condoms }\end{array}$} \\
\hline $\begin{array}{l}\text { Abstinence was preferred } \\
\text { over condom use }\end{array}$ & 21 & $77.8[57.7-91.4]$ \\
\hline $\begin{array}{l}\text { My husband is not } \\
\text { comfortable }\end{array}$ & 4 & $14.8[4.2-33.7]$ \\
\hline I am not comfortable & 2 & $7.4[0.9-24.3]$ \\
\hline
\end{tabular}




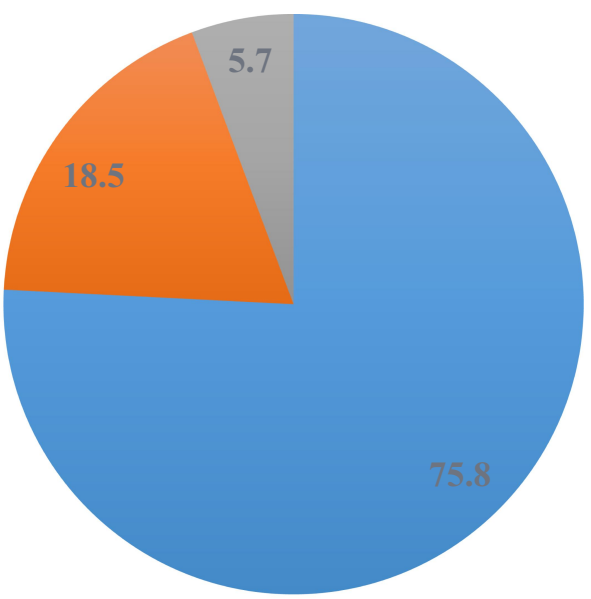

घegative $\square$ Positive $\square$ Suspicious for cancer

Figure I Result of precancerous cervical lesion screening by VIA method among women at HFSUH and Jugal hospital, January I to May 30, 2019.

\section{Prevalence of Abnormal Cervical Lesions}

A total of 594 women were screened for precancerous cervical lesions by using VIA technique. Among these, $24.2 \%$ [95\% CI $=20.8-27.9 \%]$ of participants had abnormal cervical lesions, of which $18.5 \%$ were found to be positive and $5.7 \%$ had lesions suspected to be cervical cancer (Figure 1). Twenty two (34.9\%) of HIV positive participants had abnormal cervical lesion in the current study. All women that were found to be VIA positive during screening were treated with cryotherapy on the same day and those who had suspicious lesions were referred for further investigation and management.

\section{Factors Associated with Abnormal Cervical Lesions}

In bivariate logistic regression analysis; not having formal education, not having awareness of cervical cancer, age at first sexual intercourse, ever given birth, number of births and husband's multiple sexual partner history had a significant association with abnormal cervical lesions. In multivariable logistic regression analysis; not having formal education, not having awareness of cervical cancer and husband's multiple sexual partner history were independently associated with abnormal cervical lesions. The odds of abnormal cervical lesions was 1.75 times higher among women whose husbands had history of multiple sexual partners, AOR $=1.75$ [1.13-2.7]. The odds of developing abnormal cervical lesions among women who had no formal education was 2.7 times higher than women who had educational level above $12^{\text {th }}$ grade, $\mathrm{AOR}=2.68$ [CI $=1.32-5.46]$. There was increased odds of abnormal cervical lesions among participants who had no awareness of cervical cancer, $\mathrm{AOR}=2.65[\mathrm{CI}=1.68-4.23]$ (Table 5).

\section{Discussion}

This study assessed adherence to post-cryotherapy treatment recommendations, prevalence of abnormal cervical lesions and factors associated with abnormal cervical lesions. In the current study, we used visual inspection with acetic acid (VIA) method to screen women for precancerous cervical lesions. VIA is a preferable method in low resource countries like Ethiopia because it is inexpensive and utilizes locally available supplies. One of the limitations of VIA method is its subjective nature, which may compromise the quality of the test result. However, through thorough supervision and regular monitoring, the quality of VIA test can be achieved. ${ }^{9}$ In this study, $18.5 \%$ were positive for precancerous cervical lesions and 5.7\% had an ulcer suspected to be cancer. The finding of this study concurs with results of studies from Bangladesh $(18.2 \%)^{19}$ and it is less than what was reported from southern Ethiopia (22.1\%) and Kenya (26.7\%). ${ }^{12,16}$

The difference might be due to the fact that all of the study participants of the comparative studies were HIV positive and this could increase their risk of developing precancerous lesions compared to the general population. This was also evidenced in studies from Swaziland where the presence of cervical lesions was higher among HIV positive $(22.9 \%)$ than HIV negative $(5.7 \%)$ women. ${ }^{20} \mathrm{On}$ the other hand, this finding was higher than that of studies from Cameroon (3.33\%) and Thailand (13.3\%). ${ }^{21,22}$ This discrepancy could be due to the difference in sample size. When the sample size is small, as is in the comparative studies, the chance of obtaining positive result would also be low.

According to the World Health Organization (WHO) recommendation, a woman should avoid sexual intercourse, or use condoms for one month after cryotherapy treatment to prevent infection and facilitate fast healing of the cervix. ${ }^{23}$ Majority of respondents in this study who received cryotherapy treatment adhered to the postcryotherapy treatment recommendations. More than $90 \%$ of respondents abstained from sexual intercourse or used condoms consistently for one month after cryotherapy treatment. In this study, all of the respondents who received cryotherapy treatment attended the follow up 
Table 5 Bivariate and Multivariable Logistic Regression Analysis Showing Relation Between Abnormal Cervical Lesions and Selected Variables of Respondents at HFSUH and Jugal Hospital, January I to May 30, 2019

\begin{tabular}{|c|c|c|c|c|}
\hline \multirow[t]{2}{*}{ Variables } & \multicolumn{2}{|c|}{ Abnormal Cervical Lesions (VIA Result) } & \multirow[t]{2}{*}{ COR $(95 \%$ C.I) } & \multirow[t]{2}{*}{ AOR (95\% C.I) } \\
\hline & Negative & Positive & & \\
\hline \multicolumn{5}{|l|}{ Educational level } \\
\hline No formal education & 104 & 48 & $2.39[1.28-4.45]^{* *}$ & $2.68[1.32-5.46]^{* *}$ \\
\hline Elementary level & 166 & 46 & $1.43[0.78-2.65]$ & $\mathrm{I} .80[0.89-3.67]$ \\
\hline Secondary education & 92 & 33 & $1.86[0.97-3.57]$ & $2.48[1.16-5.31]$ \\
\hline I2th grade and above & 88 & 17 & 1 & \\
\hline \multicolumn{5}{|l|}{ Awareness of cervical cancer } \\
\hline No & 214 & 95 & $2.14[1.45-3.16]^{*}$ & $2.65[1.68-4.23]^{*}$ \\
\hline Yes & 236 & 49 & 1 & 1 \\
\hline \multicolumn{5}{|l|}{ Age at first sexual intercourse } \\
\hline$<15$ & 25 & 12 & $2.19[1.02-4.72]^{*}$ & \\
\hline $15-19$ & 233 & 90 & $1.77[1.17-2.67]^{*}$ & \\
\hline$>19$ & 192 & 42 & 1 & \\
\hline \multicolumn{5}{|l|}{ Ever delivered a baby } \\
\hline No & 95 & 16 & I & \\
\hline Yes & 355 & 128 & $2.14[1.21-3.77]^{*}$ & \\
\hline \multicolumn{5}{|l|}{ Number of deliveries } \\
\hline $\mathrm{I}-3$ & 262 & 84 & 1 & \\
\hline $4-7$ & 82 & 32 & $1.22[0.76-1.96]$ & \\
\hline 8 and above & II & 12 & $3.4[1.45-7.99]^{*}$ & \\
\hline \multicolumn{5}{|l|}{ Husband's multiple sexual partner history } \\
\hline No & 415 & 128 & 1 & 1 \\
\hline Yes & 35 & 16 & $1.52[1.04-2.23]^{* *}$ & $1.75[1.13-2.70]^{* *}$ \\
\hline
\end{tabular}

Notes: ${ }^{*} p<0.05,{ }^{* *} p<0.01$.

visit at the first month. This finding is higher than what was reported from Botswana, where only $40 \%$ of participants kept their follow up visits. This might be due to the difference in health seeking behaviors between the two study populations. ${ }^{24}$

Human papilloma virus, which is the causative agent of abnormal cervical lesions is transmitted through sexual intercourse and the risk increases with having sexual intercourse with multiple partners. Women whose husbands had history of sexual contact with more than one person have increased risk of acquiring the virus. As it is evident in previous studies, being a wife of a husband who had a history of sexual intercourse with multiple partners was the major risk factor for abnormal cervical lesions and invasive cervical carcinoma. It was also found that husbands of women diagnosed with cervical cancer were more sexually active than the comparative groups. ${ }^{25,26}$ In the current study, husbands' multiple sexual partner history was among the factors that were independently associated with abnormal cervical lesions. This finding is supported by the results of studies done in Ethiopia and other countries. ${ }^{27}$

Our findings suggest that women with no formal education were found to have 2.7 times greater odds of having abnormal cervical lesions than women who attained educational status above $12^{\text {th }}$ grade. Uneducated women have limited access to information about cervical cancer and its prevention mechanisms and this may expose them to having abnormal cervical lesions. In other words, educated women have adequate information to protect themselves by practicing prevention methods such as using condoms which helps protect them from having abnormal cervical lesions. $^{28}$ This finding is in agreement with reports from Zambia, where a small proportion of women (8.6\%) tested positive for abnormal cervical lesions compared to the women with lower educational status. ${ }^{29}$

In the present study, having awareness of cervical cancer was found to be a protective factor against having abnormal cervical lesions. The odds of having abnormal cervical 
lesions were more than double among women who had no awareness of cervical cancer. Women who have awareness of cervical cancer are more likely to protect themselves by avoiding the risk factors associated with the disease. This can also be explained as, individuals who are aware of the disease have a higher chance of practicing prevention methods because of perceived susceptibility to the disease and perceived benefits of the prevention methods. ${ }^{30}$ Therefore they have less chance of developing abnormal cervical lesions. However, those women who are not aware of cervical cancer do not practice prevention methods and they have higher chance of developing abnormal cervical lesions. $^{31}$ This study has some limitation regarding the design used to measure the adherence level, as the participants were asked about their past experience, there is a chance of exposure to recall bias.

\section{Conclusion}

In this study we found that the prevalence of abnormal cervical lesions $(24.3 \%)$ was high. The federal ministry of health and other stakeholders should focus on the primary prevention method (HPV vaccination) at earlier stage to reduce the prevalence of abnormal cervical lesions in the study area. In the present study, more than ninety percent of the study participants adhered to the post-cryotherapy treatment recommendations. Having no formal education, lack of awareness of cervical cancer and having a husband with history of multiple sexual partners were independently associated with abnormal precancerous cervical lesions. Harari regional health bureau should strengthen awareness creation activities regarding cervical cancer for the community living in Harar city and nearby rural villages through community conversation programs and home to home information dissemination by health extension workers, and special focus should also be placed on uneducated women to increase their awareness of abnormal cervical lesions.

\section{Data Sharing Statement}

Data can be provided for all interested persons upon request from Elias Bekele Wakwoya.

\section{Ethics and Consent}

This study was conducted in accordance with the Declaration of Helsinki and it was approved by the Haramaya University institutional health research Ethics review committee and the approval number was (COHMS/ 10.0/2968/18). Written and signed informed consent was obtained from each study participant and head of both hospitals prior to interview as it is stated in participant information sheet. The data collection procedure was anonymous in order to keep the confidentiality of any information provided by the study participants.

\section{Acknowledgments}

The authors would like to acknowledge Center for International Reproductive Health Training (CIRHT) for funding this study and Haramaya University for its technical support during the study time.

\section{Funding}

Center for International Reproductive Health Training (CIRHT) funded this research.

\section{Disclosure}

The authors report no conflicts of interest in this work.

\section{References}

1. Bray F, Ferlay J, Soerjomataram I, Siegel RL, Torre LA, Jemal A. Global cancer statistics 2018: GLOBOCAN estimates of incidence and mortality worldwide for 36 cancers in 185 countries. CA Cancer J Clin. 2018;68(6):394-424.

2. Ferlay J, Colombet M, Soerjomataram I, et al. Estimating the global cancer incidence and mortality in 2018: GLOBOCAN sources and methods. Int $j$ Cancer. 2019;144(8):1941-1953. doi:10.1002/ijc.31937

3. Arbyn M, Weiderpass E, Bruni L, et al. Estimates of incidence and mortality of cervical cancer in 2018: a worldwide analysis. Lancet Global Health. 2020;8(2):e191-e203. doi:10.1016/S2214-109X(19) 30482-6

4. Schiffman M, Castle PE, Jeronimo J, Rodriguez AC, Wacholder S. Human papillomavirus and cervical cancer. The Lancet. 2007;370 (9590):890-907. doi:10.1016/S0140-6736(07)61416-0

5. Köse FM, Naki MM. Cervical premalignant lesions and their management. J Turk German Gynecol Assoc. 2014;15(2):109-121. doi:10.5152/jtgga.2014.29795

6. Bedell SL, Goldstein LS, Goldstein AR, Goldstein AT. Cervical cancer screening: past, present, and future. Sexual Med Rev. 2020;8 (1):28-37. doi:10.1016/j.sxmr.2019.09.005

7. Mishra GA, Pimple SA, Shastri SS. An overview of prevention and early detection of cervical cancers. Indian J Med Paediatr Oncol. 2011;32(3):125-132.

8. Luciani S, Munoz S, Gonzales M, Delgado JM, Valcarcel M. Effectiveness of cervical cancer screening using visual inspection with acetic acid in Peru. Int J Gynaecol Obstet. 2011;115(1):53-56. doi:10.1016/j.ijgo.2011.05.014

9. World Health O. Comprehensive Cervical Cancer Control: A Guide to Essential Practice. 2nd ed. Geneva: World Health Organization; 2014.

10. Shiferaw N, Salvador-Davila G, Kassahun K, et al. The single-visit approach as a cervical cancer prevention strategy among women with HIV in Ethiopia: successes and lessons learned. Glob Health Sci Pract. 2016;4(1):87-98. doi:10.9745/GHSP-D-15-00325

11. Deksissa ZM, Tesfamichael FA, Ferede HA. Prevalence and factors associated with VIA positive result among clients screened at Family Guidance Association of Ethiopia, south west area office, Jimma model clinic, Jimma, Ethiopia 2013: a cross-sectional study. BMC Res Notes. 2015;8:618. doi:10.1186/s13104-015-1594-x 
12. Gedefaw A, Astatkie A, Tessema GA. The prevalence of precancerous cervical cancer lesions among HIV-infected women in southern Ethiopia: a cross-sectional study. PLoS One. 2013;8(12):e84519e84519. doi:10.1371/journal.pone.0084519

13. Belayneh T, Mitiku H, Weldegebreal F. Precancerous cervical lesions and associated factors among HIV-infected women on ART in Amhara Regional State, Ethiopia: a hospital-based cross-sectional study. Int J Health Sci (Qassim). 2019;13(3):4-9.

14. Kassa RT. Risk factors associated with precancerous cervical lesions among women screened at Marie Stops Ethiopia, Adama town, Ethiopia 2017: a case control study. BMC Res Notes. 2018;11(1):145.

15. Juneja A, Sehgal A, Mitra A, Pandey A. A survey on risk factors associated with cervical cancer. Indian J Cancer. 2003;40(1):15-22.

16. Memiah P, Mbuthia W, Kiiru G, et al. Prevalence and risk factors associated with precancerous cervical cancer lesions among HIV-infected women in resource-limited settings. AIDS Res Treat. 2012;2012.

17. Teame H, Addissie A, Ayele W, et al. Factors associated with cervical precancerous lesions among women screened for cervical cancer in Addis Ababa, Ethiopia: A case control study. PLoS One. 2018;13(1): e0191506

18. Yazghich I, El Madani H, Baya M, Berraho M. Determinants of precancerous cervical lesions: a case-control study. Revue d'Épidémiologie et de Santé Publique. 2018;66:S293-S294. doi:10.1016/j.respe.2018.05.152

19. Bradford L, Dey B, Md S, et al. Development of a cervical cancer screening program in a slum setting using visual inspection with acetic acid: analysis of feasibility and cost. Open $J$ Obstetrics Gynecol. 2012;2:140-146. doi:10.4236/ojog.2012.22027

20. Jolly PE, Mthethwa-Hleta S, Padilla LA, et al. Screening, prevalence, and risk factors for cervical lesions among HIV positive and HIV negative women in Swaziland. BMC Public Health. 2017;17(1):218.

21. Nkfusai NC, Mubah TM, Yankam BM, Tambe TA, Cumber SN. Prevalence of precancerous cervical lesions in women attending Mezam Polyclinic Bamenda, Cameroon. Pan Afr Med J. 2019;32:174. doi:10.11604/pamj.2019.32.174.16895

22. Gaffikin L, Blumenthal PD, Emerson M, Limpaphayom K. Safety, acceptability, and feasibility of a single-visit approach to cervical-cancer prevention in rural Thailand: a demonstration project. Lancet (London, England). 2003;361(9360):814-820.
23. Health WHOR, Organization WH, Diseases WHOC, Promotion H. Comprehensive Cervical Cancer Control: A Guide to Essential Practice. second ed. World Health Organization; 2014.

24. Barchi F, Winter SC, Ketshogile FM, Ramogola-Masire D. Adherence to screening appointments in a cervical cancer clinic serving HIV-positive women in Botswana. BMC Public Health. 2019;19(1):318. doi:10.1186/s12889-019-6638-z

25. Agarwal SS, Sehgal A, Sardana S, Kumar A, Luthra UK. Role of male behavior in cervical carcinogenesis among women with one lifetime sexual partner. Cancer. 1993;72(5):1666-1669. doi:10. 1002/1097-0142(19930901)72:5<1666::AID-CNCR2820720528>3. $0 . \mathrm{CO} ; 2-\mathrm{M}$

26. Castellsagué X, Bosch FX, Muñoz N. The male role in cervical cancer. Salud Publica Mex. 2003;45(Suppl 3):S345-353. doi:10.1590/S0036-36342003000900008

27. Teame H, Addissie A, Ayele W, et al. Factors associated with cervical precancerous lesions among women screened for cervical cancer in Addis Ababa, Ethiopia: A case control study. PLoS One. 2018;13(1): e0191506.

28. Saei Ghare Naz M, Kariman N, Ebadi A, Ozgoli G, Ghasemi V, Rashidi Fakari F. Educational interventions for cervical cancer screening behavior of women: a systematic review. Asian Pac $J$ Cancer Prev. 2018;19(4):875-884.

29. Hamoonga TE, Likwa RN, Musonda P, Michelo C. Higher educational attainment associated with reduced likelihood of abnormal cervical lesions among Zambian women - a cross sectional study. BMC Cancer. 2017;17(1):681. doi:10.1186/s12885-017-3680-z

30. Glanz K, Rimer BK, Viswanath K, eds. Health Behavior and Health Education: Theory, Research, and Practice. 4th ed. San Francisco: Jossey-Bass; 2008.

31. Wilson AR, Hashibe M, Bodson J, et al. Factors related to HPV vaccine uptake and 3-dose completion among women in a low vaccination region of the USA: an observational study. BMC Women's Health. 2016;16(1):41. doi:10.1186/s12905-016-0323-5
Cancer Management and Research

\section{Publish your work in this journal}

Cancer Management and Research is an international, peer-reviewed open access journal focusing on cancer research and the optimal use of preventative and integrated treatment interventions to achieve improved outcomes, enhanced survival and quality of life for the cancer patient.
The manuscript management system is completely online and includes a very quick and fair peer-review system, which is all easy to use. Visit http://www.dovepress.com/testimonials.php to read real quotes from published authors. 